\title{
TRAUMA, NARRATIVA E MEMÓRIA NO DOCUMENTÁRIO ÔNIBUS 174
}

\author{
TRAUMA, NARRATIVE AND MEMORY IN DOCUMENTARY BUS 174 \\ TRAUMA, NARRATIVA Y MEMORIA EN EL DOCUMENTAL AUTOBÚS 174
}

Gustavo Souza'

Resumo: ônibus 174 (José Padilha, 2002) aborda o sequestro de um ônibus (linha 174) no Rio de Janeiro, em 2000. O documentário narra de modo sequencial o início, o desenrolar e o término do episódio e, em paralelo, conta a história de vida do sequestrador Sandro do Nascimento. É essa dualidade que interessa a este trabalho, cujo foco se concentra nos depoimentos e imagens de arquivo à luz da discussão sobre o trauma e seus temas correlatos, como a memória e a narrativa. Parte-se da ideia de que o trauma é fruto de uma conjuntura social e cultural, sempre relacionado a demandas contextuais. Por isso, o modo como o documentário narra a história do protagonista aciona a hipótese de que, ao construir uma memória indesejada, Ônibus 174 dá a ver uma vida no trauma, ou seja, uma condição superlativa de um estado de desigualdade que escapa à racionalidade e interrompe laços sociais e pessoais.

Palavras-chave: Documentário. Trauma. Memória.

Abstract: bus 174 (José Padilha, 2002) deals with the kidnapping of a bus (line 174) in Rio de Janeiro city in 2000. The documentary narrates in a sequential way the beginning, the evolution and the end of the event and, in parallel, tells the story of life of the kidnapper Sandro do Nascimento. It is this duality that interests this article, which focuses on the testimonies and archival images in the light of the discussion about trauma and its related themes, such as memory and narrative. It starts from the idea that the trauma is the fruit of a social and cultural conjuncture, always related to contextual demands. Therefore, the way in which the documentary narrates the story of

Professor do Programa de Pós-Graduação em Comunicação e Cultura Midiática da Universidade Paulista (UNIP), São Paulo, SP, Brasil. http://orcid.org/0000-0003-0134-9207. E-mail: gustavo03@uol.com.br 
the protagonist triggers the hypothesis that, in constructing an unwanted memory, Bus 174 gives a life in trauma, that is, a superlative condition of a state of inequality that escapes rationality and disrupts social and personal ties.

Keywords: Documentary. Trauma. Memory.

Resumen: autobús 174 (José Padilha, 2002) aborda el secuestro de un autobús (línea 174) en Río de Janeiro en 2000. El documental narra de modo secuencial el inicio, el desarrollo y el final del episodio y, en paralelo, cuenta la historia de la vida del secuestrador Sandro do Nascimento. Es esa dualidad la que interesa a este trabajo, cuyo foco se concentra en los testimonios e imágenes de archivo a la luz de la discusión sobre el trauma y sus temas relacionados, como la memoria y la narrativa. Se parte de la idea de que el trauma es fruto de una coyuntura social y cultural, siempre relacionada con demandas contextuales. Por eso, el modo en que el documental narra la historia del protagonista acciona la hipótesis de que, al construir una memoria indeseada, Autobús 174 da a ver una vida en el trauma, o sea, una condición superlativa de un estado de desigualdad que escapa a la racionalidad y interrumpe lazos sociales y personales.

Palavras-chave: Documental. Trauma. Memoria.

\section{Introdução}

A produção de cinema no Brasil da primeira década deste século foi fortemente marcada por filmes em que temas como pobreza, marginalidade e violência urbana se tornaram centrais. Na ficção ou no documentário, são inúmeras as obras que buscam apresentar, problematizar ou compreender essa realidade. Entre elas, está Ônibus 174 (José Padilha, 2002) - documentário sobre o sequestro de um ônibus na tarde de 12 de junho de 2000, no bairro do Jardim Botânico, no Rio de Janeiro, transmitido ao vivo por cerca de cinco horas, e que terminou com a morte da refém, Geísa Gonçalves, e do sequestrador, Sandro do Nascimento, pela polícia. O filme é sobre o sequestro, mas não somente. Ele também narra a história de vida de Sandro e apresenta o contexto de onde emergem acontecimentos traumáticos como este.

Em suas inúmeras abordagens teóricas - da psicanálise à sociologia, da história à filosofia -, há um conjunto de aspectos que converge para uma definição comum de trauma: trata-se de um fato inesperado e que deixa consequências indeléveis. Em meio a essa diversidade, parto das pistas fornecidas pelo corpus para encontrar uma perspectiva teórica a ele correlata. Os cinco primeiros minutos do filme já anunciam a organização narrativa que se verá até o final. $\mathrm{Na}$ abertura, imagens aéreas mostram um cartão-postal mundialmente conhecido: 
a orla da cidade do Rio de Janeiro. Na sequência, vários garotos contam sobre as estratégias para sobreviver nas ruas e, em seguida, vê-se Sandro e os reféns dentro do ônibus. Essa passagem revela um movimento da montagem que parte do contexto para chegar ao sequestro, e isso me conduzirá ao conceito de trauma cultural (ALEXANDER, 2004; SMELSER, 2004), cuja premissa é conceber o trauma como uma atribuição socialmente mediada, isto é, ele não ocorre de modo causal, mas como parte de um processo dentro de uma lógica mais ampla.

No caso exposto pelo filme, o trauma não se restringe apenas ao sequestro e aos seus desdobramentos, mas à própria vida de Sandro: aos seis anos, presenciou o assassinato da mãe; depois desse episódio, passou morar na rua, onde sobreviveu à chacina da Candelária² em 1993 e, aos 22, protagonizou o sequestro do ônibus. Com esse aspecto como norte, o procedimento de análise privilegia a identificação dos materiais presentes no documentário, seus modos de composição e a arquitetura da narrativa (TEIXEIRA, 2005). As atenções se voltam, então, para os depoimentos e às imagens de arquivo, cuja organização pela montagem aciona a hipótese de que Ônibus 174 dá a ver uma vida no trauma: ao descartar a ideia de que o sequestro seja um caso isolado de violência, desloca-se o trauma da esfera individual para a coletiva, indicando para ele uma condição perene em vez de seu caráter excepcional.

Abordar Ônibus 174 pelo viés de uma narrativa do trauma se justifica porque, para além dos debates sobre os limites da representação de experiências traumáticas, a relação entre trauma e imagem existe desde Charcot $^{3}$ - que, no século XIX, fotografava suas pacientes - até os mais recentes atentados na Europa, por exemplo. O que conecta essas diferentes experiências no tempo e no espaço é exatamente a produção de imagens que, a partir da década de 1980, tem se intensificado de modo que hoje a discussão sobre esse assunto passa em grande medida por suas evidências visuais. A aproximação entre documentário e trauma abre um precedente para a teoria de o trauma contribuir com o debate sobre culturas mediadas por imagens e linguagens da violência, como é o caso da brasileira, pois se um determinado evento se estabelece como um trauma nacional, do qual a sociedade tem que se responsabilizar de alguma maneira, essa condição se mantém de modo contínuo ao desafiar a compreensão e assimilação por meio de interpretações do passado ainda que recente. Essa tarefa se torna mais tangível quando o foco se

\footnotetext{
2 Encabeçada por policiais, ocorreu no dia de 23 julho de 1993 e resultou na morte de oito jovens, seis deles menores de idade, que dormiam próximo à igreja da Candelária no centro do Rio de Janeiro.

3 Jean-Martin Charcot (1825-1893) foi um médico francês da área de psiquiatria e neurologia. Defendia a hipnose como método de tratamento da histeria.
} 
direciona às ocorrências e demandas locais. Isso implica abandonar o ponto de vista eurocêntrico que restringe os estudos do trauma ao holocausto da Segunda Guerra Mundial e aos atentados de 11 de setembro de 2001.

É preciso, além disso, questionar como a cultura das mídias, especialmente das mídias audiovisuais, tem contribuído para o entendimento do trauma não somente como uma condição psicológica individual, mas derivada de experiências sociais ou culturais. É provável que o cinema (o vídeo também incluído) seja a forma visual que mais frequentemente, e por meio dos mais diversos alcances, tem representado e explorado uma miríade de maneiras em que o trauma se manifesta na experiência subjetiva e na cultura.

\section{Trauma cultural: do contexto para o específico}

Outros trabalhos sobre este documentário debatem desde as políticas de representação da violência no cinema brasileiro da retomada (HAMBURGER, 2005), passando pelo modo como, para construir uma memória para Sandro, o filme lança mão de estratégias e recursos do melodrama (BALTAR, 2007), a maneira como o filme se constitui como um memorial (LEU, 2008) até as ideologias e os efeitos das transmissões ao vivo (VILLAREJO, 2006). Embora nesses dois últimos textos haja o reconhecimento do sequestro como um evento traumático, o foco em cada um deles, como apontando, é outro. Além de corroborar tal reconhecimento, quero propor aqui uma discussão sobre esse documentário em uma aproximação com as teorias do trauma.

A narrativa de Ônibus 174 é composta por dois elementos centrais: depoimentos e imagens de arquivo. No primeiro caso, falam reféns, amigos de Sandro, policiais, agentes penitenciários, jornalistas, uma tia, sua mãe de criação, uma assistente social e um antropólogo. Já as imagens de arquivo, concedidas pelas emissoras de televisão Rede Globo, SBT e Record e também pela Companhia de Engenharia de Tráfego do Rio de Janeiro (CET Rio), mostram a articulação da polícia e da imprensa em torno do ônibus cercado. Por meio desse material, organizado numa montagem que constantemente vai ao passado e volta ao presente, o filme narra o sequestro e, ao mesmo tempo, elabora uma história para Sandro, que, pelas lentes das transmissões ao vivo, era apenas um marginal na tentativa de levar o sequestro a adiante.

Antes de me concentrar na análise desse material fílmico, é importante fixar as bases em torno do conceito de trauma devido à sua amplitude e alcance teórico, o que o faz ser debatido por inúmeras áreas de conhecimento. Ressaltei ante- 
riormente a dimensão contextual do conceito de trauma aqui adotado. Contudo, essa perspectiva já constava nas reflexões de autores como Benjamin e Bakhtin, que, em diálogo com Freud - responsável por aprimorar o conceito de trauma a partir de suas investigações sobre a histeria -, ressaltaram a dimensão social das formações subjetivas, bem como das experiências traumáticas. Trata-se de uma discussão que antecede a expansão teórico-metodológica que o conceito de trauma experimentaria a partir da década de 1970, quando outras áreas do saber, como a sociologia, por exemplo, passaram a se interessar pela noção de trauma ao contrapor o trauma psicológico (individual) ao trauma social ou cultural (coletivo), cujo ponto de partida se encontra na obra Everything in its path, de Kai Erikson (1976).

Ao comentar o estado de choque dos soldados que lutaram na Primeira Guerra Mundial, Benjamin deslocou o foco da esfera psicanalítica com suas terapias individuais, para considerar que "estar exposto ao choque 4 se tornou a norma" (BENJAMIN, 1989, p. 110), em um contexto em que a assimilação de uma experiência traumática como a guerra, por exemplo, se torna difícil. Esse ponto de vista é fundamental para o entendimento da modernidade e para a defesa do porquê de as sociedades modernas serem marcadas pela crise da experiência. Por sua constância no cotidiano, o choque seria responsável, então, por esvaziá-la. Já Bakhtin (2007) não estabelece uma discussão stricto sensu sobre o trauma, mas procura debater o pensamento freudiano ao privilegiar sua dimensão ideológica. Ele salienta a importância das instâncias contextuais para a melhor compreensão do inconsciente, contribuindo, assim, para a construção de um viés socio-histórico para o entendimento do que se passa na mente humana.

A reflexão de ambos reverbera a conjuntura social e política do entreguerras, sendo necessário, portanto, a aproximação com perspectivas que a estendam. Nesse horizonte, os pontos de vista desses dois autores servirão como inspiração, uma espécie de moldura para este trabalho, porque, embora haja uma ênfase no contexto social, eles não estabelecem uma rígida separação entre o subjetivo e as experiências na coletividade, mas prezam por uma intersecção entre eles. Tal separação, inclusive, parece refletir mais uma disputa entre áreas do que necessariamente o que ocorre de fato.

Ao tomar o corpus como guia para a seleção das abordagens conceituais, a que se alinha às perspectivas postas acima é a noção cultural de trauma, caracterizada por um sentimento negativo, difícil de lidar ou esquecer, e diretamente relacionado às formações sociais e culturais de uma comunidade (SMELSER, 2004; 
ALEXANDER, 2004). O modo como Padilha constrói, paralelamente, a história do sequestro e a história de Sandro não deixa dúvidas sobre esses aspectos, porém há algo sobre a terceira característica que é preciso evidenciar: não basta apenas reconhecer que o trauma deriva de um determinado contexto social, mas perceber possíveis transformações que o acontecimento traumático provoca na sociedade. No caso abordado pelo documentário, não é possível esperar por mudanças nas estruturas sociais e culturais brasileiras, afinal outros traumas continuaram a acontecer depois desse, porque ignorá-los é dar margem para a repetição. Assim, o enfrentamento do trauma cede espaço para o reconhecimento de que ele pode não ser uma eventualidade, mas uma condição. Para além da listagem de características, não se pode perder de vista que "traumas culturais não nascem, se criam como produto da história"5 (SMELSER, 2004, p. 37, tradução nossa) ou "o trauma não é algo que existe de forma natural, ele é construído pela sociedade" (ALEXANDER, 2004, p. 2, tradução nossa), isto é, no cenário brasileiro, resguardadas as suas especificidades e disparidades sociais, não soa despropositado que em algum momento eclodisse o que se vê em Ônibus 174. Seria preciso uma investigação mais profunda para afirmar que a especificidade brasileira do trauma social é o seu caráter perpétuo, mas aqui o foco não é o estudo trauma em si, mas o modo como ele se articula com o documentário. O objetivo não é mergulhar nos meandros conceituais, mas apresentá-los para discutir como Ônibus 174 materializa em imagem e som tais aspectos. Por isso, é preciso se concentrar nas suas condições de produção, cujas interpretações no âmbito acadêmico encontram-se cada vez mais sujeitas a ampliações e relativizações.?

Para tanto, é necessário perceber como se articula no documentário a relação entre narrativa, memória e trauma, pois, se a memória encontra na narrativa o seu suporte (SARLO, 2007), é por meio do trabalho de ativação da memória que um determinado evento pode ser lido como traumático. Nessa perspectiva, não

\footnotetext{
5 Do original: Cultural traumas are for the most part historically made, no born.

6 Do original: Trauma is not something naturally existing; it is something constructed by society.

7 "O processo mediante do qual uma sintomatologia (do trauma) se converte em um recurso político é um tema interessante em si mesmo e merece uma reflexão científica. A tendência que tem o trauma a expandir-se e incluir constantemente novos fenômenos, somado à sua transformação em uma questão econômica, política e moral, tem criado, o ponto vista científico, um enredo que dificulta as intenções de sua formulação e compreensão" (SMELSER, 2004, p. 59). Do original: The process involved in making a symptomatology (trauma) into a political resource is an interesting subject in and of itself, and deserving of scientific understanding. The tendency for the notion of trauma to sprawl and include ever-new ranges of phenomena - plus the economization, politicization, and moralization of trauma - has, from a scientific stand-point, created a jungle that defies attempts as scientific formulation and understanding.
} 
se pode desprezar também o papel e a importância das mídias na discussão sobre memória (HUYSSEN, 2000; WATERSON, 2007) e sobre trauma (BRODERICK; TRAVERSO, 2011; WALKER, 2005). Pode-se entender esses três elementos, respectivamente, como o meio de expressão, a matéria-prima e possíveis consequências. É evidente que entre eles há uma íntima relação, e separá-los tem o intuito apenas de facilitar o desenvolvimento da análise.

Desse modo, observa-se no documentário um espaço para articulação triangular entre trauma, narrativa e memória. A perspectiva adotada é de que essas três dimensões se entrelaçam de forma contígua para construir imagens, sons e discursos. Não se trata de privilegiar nenhum dos ângulos do triângulo assim definido, mas de mostrar a peculiaridade da relação que cada um deles apresenta no documentário selecionado. Narrativa, memória e trauma são planos irredutíveis, mas que podem ser investigados segundo uma mesma estratégia: as instâncias da composição narrativa corresponderão, mutuamente, às esferas da memória, e estas, por sua vez, às do trauma.

\section{As dualidades da narrativa}

Se visto de modo apressado, o documentário será o lugar em que a captação de imagens e sons ocorre de modo improvisado, acidental ou não planejado, como se o diretor e sua câmera estivessem sempre na hora e no local certos para registrar o que desejam. Na prática, esse tipo de argumento pouco se sustenta, porque desde Nanook, o esquimó (Nanook of the north, 1922) ${ }^{8}$, de Robert Flaherty, sabe-se que há planejamento, preparação e repetição do que é gravado. Esse diretor percebeu que apenas o registro é insuficiente. Era preciso, a partir dele, criar uma narrativa, dramatizar o cotidiano da comunidade que estava filmando - estratégia que se tornou vital para o desenvolvimento do documentário (WINSTON, 2017). Muito do que se vê no filme foi pensado para a câmera, como, por exemplo, a pesca da morsa ou a construção de um iglu. Desse modo, em seu nascimento, a relação entre documentário e a narrativa já estava dada. Cristaliza-se o encadeamento de ações e uma trajetória para indivíduos que experimentam a passagem de pessoa para personagem.

Ao aproximar essa discussão de Ônibus 174, o que faz José Padilha é utilizar o documentário para narrar a história de Sandro do Nascimento, concebendo-o,

8 Documentário que mostra o cotidiano de uma comunidade inuit (indígenas esquimós) que vive no Polo Norte. Embora não haja consenso, é considerado o primeiro documentário da história do cinema. 
de acordo com Baltar (2007), como um personagem, ao lançar mão de estratégias que dramatizam o assunto em ao menos dois sentidos correlatos: o drama como narração e o drama que aciona as emoções. A partir disso, a montagem organiza simultaneamente dois movimentos: um cronológico, referente ao sequestro que narra seu início, desenvolvimento e término; e outro não linear, que articula a história de vida de Sandro, principalmente por meio dos depoimentos de amigos, uma tia, a mãe de criação e a assistente social Ivone Bezerra, em um constante vai e vem entre seu passado e o sequestro. Essa dualidade não se configura apenas como moldura da narrativa de Ônibus 174, ela também a constitui. Como apontado na introdução, o movimento da montagem corrobora com o esquema que vai do geral ao particular, mas não nos moldes dos documentários de tese, que elegiam um grande tema e utilizavam as pessoas para confirmar o ponto de vista prévio do diretor. ${ }^{9}$ Ao contrário, esse filme fornece "um feroz argumento contra as tensões do individualismo anglo-americano no cinema documentário"10 (VILLAREJO, 2006, p. 116). Essa interpretação é, sem dúvida, válida. Porém, mais que uma resposta ao individualismo, como sugere acima Villarejo, esse documentário permite também pensar as práticas jornalísticas, especialmente o jornalismo televisivo, cuja cobertura ancorou-se basicamente nos acontecimentos do calor da hora, o que induz mais facilmente a um tratamento superficial do episódio em que a complexidade dos atores sociais envolvidos, por exemplo, ganha pouco espaço. Apropriadas pela narrativa documental, as imagens das coberturas das redes de televisão materializam visualmente aquilo que muitos depoentes falam, bem como instigam a crítica ao modus operandi da mídia brasileira frente a acontecimentos como esse. Não é objetivo deste trabalho detalhar os meandros relativos a este tópico, pois isso conduziria o texto a uma digressão, mas, por outro lado, a sua menção é ao menos necessária, tendo em vista a repetição de tais práticas, como nas coberturas do sequestro da estudante Eloá Pimentel ou da morte de Isabella Nordoni, ambos em 2008.

Passados 16 anos da realização deste documentário, sua força narrativa reside na recusa aos dualismos do tipo bom versus mau ao apontar para as inúmeras facetas que compõem a personalidade de Sandro do Nascimento, o que contribui para o entendimento dos motivos do sequestro. Trazido para o contexto

\footnotetext{
9 A identificação do esquema geral/particular foi feita por Jean-Claude Bernardet em sua análise de Viramundo (Geraldo Sarno, 1965), documentário sobre a migração do Nordeste para o Sudeste. Para mais informações, ver Bernardet (2003).

10 Como exemplos dessa tendência, a autora cita Supersize me (Morgan Spurlock, 2004) e Tarnation (Jonathan Caouette, 2003).
} 
atual, em que se reforça cada vez mais a polarização que defende que bandido bom é bandido morto, distanciar-se desse ponto de vista e das limitações da factualidade rumo à história de vida de Sandro, faz com que Ônibus 174 trafegue, antecipadamente, na contramão de imaginários e discursos que hoje circulam sobre as questões relacionadas à marginalidade e à violência urbana.

Do contexto para o específico, a intenção é mostrar que o sequestro (e os seus desdobramentos) não pode ser visto como um caso à parte de violência, mas como um episódio que integra uma complexa rede com diversos agentes sociais e grupos em conflito. Assim, a dualidade entre passado e presente é preenchida, no plano interno da narrativa, por outras: 1) marginalidade e regeneração, uma vez que o filme se vale de boletins de ocorrência que registram alguns crimes cometidos por Sandro, mas também mostra as suas tentativas em deixar a criminalidade; 2 ) a casa e a rua como espaços do trauma, pois ele presenciou o assassinato da mãe e sobreviveu à chacina da Candelária; 3) a cidade cartão-postal, na abertura do filme, com imagens áreas que mostram a orla do Rio de Janeiro, e a cidade partida, com seus morros e favelas apresentados também na mesma composição imagética; 4) ameaça e segurança, quando no início do sequestro, ele tenta esconder o rosto da imprensa para depois perceber que a presença das câmeras impediria que um tiro fosse disparado contra ele; 5) ficção e realidade, pois Sandro combinou com algumas reféns que simulassem desespero, enquanto ele fingia atirar em outra ou gritava pela janela do ônibus: "você viu o filme [Velocidade Máxima] ontem, sargento? O bagulho aqui é mais sério, isso aqui não é filme, não!"1.

Esses dois últimos pontos são fornecidos pelas imagens das emissoras de TV, que num primeiro momento, permitiram o acesso ao evento em tempo real, para depois servirem de arquivo para o documentário, conferindo-lhes a possibilidade de contextualizar e comprovar o que falam alguns depoentes. Essas mesmas imagens também operam em uma chave dual quando mostram, por exemplo, que nem Sandro e nem a polícia pareciam saber o que estavam fazendo, isto é, vê-se uma polícia mal equipada e taticamente confusa, e um assalto frustrado que se transformou em um sequestro de dimensão nacional. A confusão de Sandro é reiterada por vários depoimentos, de policiais a traficantes, que reforçam o quanto suas estratégias beiraram o amadorismo, de tão equivocadas.

A exceção à dualidade ocorre quando o filme constrói Sandro como personagem. Se, em um primeiro instante, pode-se perceber a existência de um

11 Trecho transcrito de Ônibus 174 (Padilha, 2002). 
Sandro-sequestrador e de um Sandro para além do sequestro, a opção do documentário será não ocultar nenhuma dessas duas dimensões, mas apostar na segunda possibilidade, fornecendo os subsídios para que se saiba que quem foi esse rapaz que, pelas lentes das emissoras de televisão, não passaria de um marginal que parou o País na tarde de 12 de junho de 2000. Para isso, deve-se evitar ver o filme "em uma chave melodramática simples, em que se opõem bons e maus" (HAMBURGER, 2005, p. 201), pois ele investirá na construção de uma memória para Sandro por meio de uma série de depoimentos (BALTAR, 2007).

Essas dualidades da narrativa reforçam o caráter traumático do acontecimento, pois permitem saber sobre o sequestro, mas não somente. Aqui o trauma é visto como um modo engajado a diversas expressões de conflitos sociais e à representação dos sofrimentos pessoal e coletivo. Ao voltar ao passado e desvelar as atrocidades pelas quais Sandro passou, o documentário evidencia um aspecto para além do sequestro em que vida e trauma se confundem, bem como seus respectivos papéis, que se alternam entre agente e vítima da violência. Discutirei esses papéis adiante, por agora é preciso não perder de vista a relação entre trauma, narrativa e memória.

\section{Uma memória indesejada}

Em inúmeros documentários sobre acontecimentos traumáticos, é comum que vítimas ou sobreviventes prestem depoimento. Ônibus 174 não foge à regra. Três reféns falam para o filme. ${ }^{2}$ Porém, como o acesso à versão de Sandro é impossível, sua memória, como já dito, será construída por outras pessoas, o que encaminha a questão a um paradoxo: como representar o ausente? Sobre esse ponto, Sarlo afirma que o testemunho de um sobrevivente toma o lugar de quem morreu, constituindo-se como uma "matéria-prima" (SARLO, 2007, p. 35) capaz de comunicar, ainda que de modo incompleto, pois "todo testemunho quer ser acreditado, mas nem sempre traz em si mesmo as provas pelas quais se pode comprovar sua veracidade; e elas devem vir de fora" (SARLO, 2007, p. 37). Em Ônibus 174, esse vir de fora se materializa nas imagens de arquivo que, quando justapostas aos testemunhos, reordenam a existência de Sandro entre a ausência e a substituição.

A representação audiovisual da memória, como propõe MacDougall (1998), pode ocorrer por meio do visual, da fala, sons, gestos e movimentos, mas sem 0

12 Há uma quarta refém, Damiana, que parou de falar depois do sequestro. Ela se comunica por meio de bilhetes. Há outra entrevistada que mostra o lugar onde Sandro e seus amigos dormiam próximo à igreja da Candelária, mas o filme não deixa claro se ela é também uma sobrevivente dessa chacina. 
intuito de criar uma "memória total" (MACDOUGALL, 1998, p. 241), pois é incerta e ambígua a conexão entre a construção do passado por meio de reminiscências e a construção da experiência atual. Ainda assim, Ônibus 174 recorre a muitos desses recursos para preencher o vazio deixado por Sandro.

Nos depoimentos das reféns ${ }^{13}$, destaca-se não somente a descrição do que ocorreu no ônibus, como também uma espécie de análise do fato:

\footnotetext{
o prolongamento daquela situação também servia como um espaço para significar alguma coisa pra alguém, como um espaço de mostrar que ele tinha poder, de mostrar que ele existia. Enfim, e isso era uma coisa tão fundamental quanto resolver a situação e sair dali vivo, então nesse sentido as câmeras de televisão importavam pra ele ${ }^{14}$.
}

Nesse caso, o sentimento negativo é suplantado pela intenção de extrair conclusões que, no calor da hora, não seriam possíveis. Essa é, inclusive, uma das características das narrativas do trauma, pois o imediatismo dos fatos interessa mais diretamente ao jornalismo do que ao documentário.

A capacidade analítica de alguns entrevistados (não somente reféns, mas também integrantes da polícia, como Rodrigo Pimentel sobre o perfil do policial militar) se torna um importante aspecto para a construção do ponto de vista de que Sandro, mesmo sendo agente da violência em muitos momentos, como evidenciam diversos boletins de ocorrências e suas passagens por prisões, é no fim da linha, mais vítima que agente. Para dar visibilidade a esse enfoque, o documentário entrelaça na montagem tais falas com as imagens de arquivo. Logo após a abordagem do assassinato da mãe de Sandro, alternadamente se vê o depoimento de sua tia e o depoimento de uma refém. Este último trata de um momento de aproximação com as reféns quando uma delas indagou: "você sabe quem é a maior vítima nessa história toda? Você"15. Durante sua fala, as imagens de arquivo mostram a interação entre o sequestrador e as reféns no fundo do ônibus, enquanto o depoimento da tia retoma o momento da reação de Sandro frente ao assassinato da mãe. Essas imagens de arquivo exercem dupla função: permitem visualizar aquilo que é dito pela refém, minimizando, de alguma forma, as lacunas do testemunho, e, quando justapostas aos depoimentos que voltam ao passado, atualizam o presente, em uma espécie de quebra-cabeças que, peça

\footnotetext{
13 Os depoentes não são creditados.

14 Trecho transcrito de Ônibus 174 (Padilha, 2002).

15 Trecho transcrito de Ônibus 174 (Padilha, 2002).
} 
a peça, fornece as informações sobre a vida de Sandro e revela que os papéis de vítima e agente do trauma, neste caso, podem variar. É essa a tese que o documentário procurar defender e, para isso, lança mão de outros recursos, como a música que exerce um papel crucial na mobilização das emoções, intensificando a carga dramática do episódio (HAMBURGER, 2005; BALTAR, 2007).

Como observou Mariana Baltar, a construção de uma memória tira Sandro da esfera da marginalidade e favorece "um sentimento de compaixão com o personagem" (BALTAR, 2007, p. 147). Ainda que o documentário seja tradicional em certos aspectos - dos entrevistados enquadrados em plano médio ou close up ao ritmo narrativo folhetinesco com apresentação da trama, conflito e resolução do conflito -, a memória que ele constrói é insistente e incômoda, pois se trata de alguém que a sociedade não quer. Embora prevaleça Sandro como vítima, esse processo, entretanto, se dá por meio de uma confrontação, já que nem todos os depoimentos apresentam a compaixão sugerida pelo filme. A memória de Sandro é também construída por sentimentos negativos em dois momentos: no depoimento de Damiana, que depois do sequestro, parou de falar e só se comunica por meio de mensagens escritas. Sua filha é a sua porta-voz e, em seu depoimento, ela se queixa das inúmeras oportunidades perdidas pela polícia para encerrar o sequestro. Prevalece em sua fala um tom que condena, duplamente, a ineficaz ação policial e Sandro. O sentimento negativo que caracteriza o trauma é mais evidente no depoimento de alguém próximo a Geísa, que lamenta sua morte:

Geísa tinha 20 anos, tinha uma vida toda pela frente, mas ninguém pensou nisso. A gente estava na nossa vida, simples, comum, quieta no nosso canto, feliz, planejando várias coisas, pra depois acabar numa poça de sangue ${ }^{16}$.

Além do sentimento de revolta e de não compaixão em relação a Sandro, há também a omissão sobre o desfecho do sequestro, conforme o depoimento do Capitão Batista: "Não tenho opinião sobre a morte de Sandro e nem pretendo discorrer sobre isso"17. Sobre essa opção, Maria Rita Kehl apresenta um ponto de vista, que, mesmo se referindo ao período da ditadura militar no Brasil, é útil também para se pensar os desdobramentos apresentados pelo documentário: "não há reação mais nefasta diante de um trauma social do que a política do

\footnotetext{
16 Trecho transcrito de Ônibus 174 (Padilha, 2002).
}

17 Trecho transcrito de Ônibus 174 (Padilha, 2002). 
silêncio e do esquecimento, que empurra para fora dos limites da simbolização as piores passagens da história de uma sociedade" (KEHL, 2010, p. 126). Nesse caso, o silêncio não é uma ausência, é uma presença de outra ordem, que ao mesmo tempo atesta o despreparo e os abusos de poder ocorridos.

Os depoimentos da filha de Damiana, de (provavelmente) um parente de Geísa e do Capitão Batista, quando articulados a outros que ressaltam um Sandro não violento e de bom caráter, revelam que a construção de uma memória - ainda mais uma memória subalterna e indesejada - se dá em disputa. Compaixão, revolta e omissão compõem, assim, a memória de Sandro e ajudam a sustentar a ideia de sua condição de vítima. Se a memória é seletiva, ela é também ideológica (MACDOUGALL, 1998), pois não se limita a narrar, ela também fixa um ponto de vista.

Em Ônibus 174, a memória é construída a partir do presente, na arena da confrontação. Em qualquer formação social, há muitas memórias que convivem (umas hegemônicas, outras marginais) e é a singularidade histórica, social e cultural que faz com que os sujeitos recordem de maneiras específicas, ou seja, a memória não está ali, esperando para ser contada. Paul Ricœur (2007) ressalta que o passado é o que não pode ser mudado, mas o que não é fixo é o significado do que aconteceu. Essa interpretação só pode se estabelecer no presente ou, melhor, nos sucessivos presentes nos quais a experiência é pensada. Desse modo, o filme fixa no tempo uma memória que se expande ao espaço. Se, a partir da mídia, é possível dar sentido a certa experiência pela ativação da memória, ela só faz sentido quando se considera que "o lugar político das práticas de memória", como salienta Huyssen (2000, p. 17), "é ainda nacional e não pós-nacional" (2000, p. 17). Por esse motivo, direcionar o olhar para os nossos traumas torna-se importante porque eles dizem respeito às nossas incertezas, conjunturas e modos de ser. E tão importante quanto isso é atentar para os materiais midiáticos e audiovisuais que a eles se reportam, pois é o tempo da memória que permite a arte do documentário. Torna-se, portanto, imprescindível o debate sobre o contexto social que prepara o terreno para a irrupção de acontecimentos traumáticos ou, em última instância, para uma vida no trauma. Ônibus 174 não se esquiva dessa tarefa.

\section{A vida no trauma}

Para fugir da armadilha de ver o sequestro como um caso isolado de violência, Ônibus 174 privilegia também uma possível análise de como a sociedade brasileira lida com os que foram banidos do exercício da cidadania. Se o trauma produz 
histórias e sujeitos, estender a discussão a outros Sandros se torna, portanto, inevitável. Esse debate é fornecido pelo antropólogo Luiz Eduardo Soares que, como uma espécie de personagem-explicador, apresenta o binômio visibilidade versus invisibilidade como uma chave interpretativa para a existência de tantos "meninos invisíveis":

Esses meninos estão famintos de reconhecimento. O menino, negro, pobre (...) transita pelas ruas invisível. Há duas maneiras de se produzir invisibilidade: esse menino é invisível porque nós não o vemos, nós negligenciamos a sua presença, porque projetamos sobre ele um estigma, uma caricatura, um preconceito (...), a caricatura que nós com os nossos preconceitos projetamos. ${ }^{18}$

Não entrarei no mérito das ideias de Soares (2005) ${ }^{19}$, mas é preciso verificar a relação entre as imagens que vemos e o conteúdo de seu depoimento. Enquanto Soares fala sobre a produção de invisibilidade social, as imagens mostram garotos fazendo malabares no sinal de trânsito. Nesta sequência, o malabarismo serve como metáfora sintetizadora da vida desses garotos, pois viver na invisibilidade não deixa de ser um tipo de malabarismo. São outros Sandros em busca de atenção, porém, enquanto fazer malabares e o modo como o sequestro se desenrolou podem ser vistos como um "ato de performance" (BALTAR, 2007,). 0 que distancia Sandro e os garotos malabaristas é o uso da violência como uma estratégia para sair da invisibilidade. Os meninos do sinal fazem sua performance e permanecem invisíveis porque ela é pacífica. Sandro performa, por exemplo, ao apontar a arma para a cabeça de uma refém e, assim, as atenções se voltam para ele. Isso permite ao debate aproximar desigualdade e trauma. Sendo o primeiro um significativo aspecto da nossa constituição social e o segundo, uma de suas possíveis materializações, ambos caminham em paralelo e o evento traumático seria, então, o estopim de tal processo.

Nessa perspectiva, Ônibus 174 aponta para o seguinte ponto: se o trauma social é fruto de uma conjuntura perene e injusta, pode-se, então, afirmar a existência de vidas no trauma. Não se trata, contudo, de tomar a expressão ao pé da letra, pois já foi dito que o trauma costuma ser um fato inesperado e não normativo, mas de perceber como repetidas situações traumáticas vividas por uma mesma pessoa moldam decisões e comportamentos. A vida no trauma seria uma

18 Trecho transcrito de Ônibus 174 (Padilha, 2002).

19 Para mais detalhes, ver Soares et al. (2005). 
condição superlativa de um estado de desigualdade que escapa à racionalidade e interrompe laços sociais e pessoais, afetando os marcos referencias do indivíduo e outras necessidades subjetivas e estruturais relacionadas. Por mais dura que seja a vida no trauma, ela pode instigar as coletividades a definirem novas formas de responsabilidade moral e novas direções para o curso da ação política.

O resgate da história de vida de Sandro mostra que a relação entre desigualdade e trauma não é somente de causa e efeito, mas cíclica. A observação mais detalhada de um dos dualismos da narrativa deste documentário anteriormente apontado - a casa e a rua como lugares do trauma -, permite o andamento da discussão. Para isso, busco impulso no debate sobre como procedimentos e comportamentos em casa e na rua dizem bastante sobre a nossa formação social (DAMATTA,1997). ${ }^{20}$ Sendo espaços que exigem dinâmicas e performances diferentes, o contexto social brasileiro permite que ações inicialmente previstas para a casa ocorram também na rua. Aqui, a casa e a rua servem de inspiração, porque o trauma retratado em Ônibus 174 embaralha de alguma maneira suas ordenações e posicionamentos. Quando me refiro à inspiração é em seu sentido stricto, não como um eufemismo para a aplicação, pois para Sandro a casa foi, em um primeiro instante, não um lugar de segurança, mas de uma experiência traumática: o assassinato da mãe. De acordo com o depoimento de Ivone Bezerra, esse acontecimento o fez romper os laços familiares para, em seguida, buscar na rua uma alternativa ao que talvez não tenha encontrado em casa. Para fugir do trauma, Sandro foi para rua e, apesar de todas as adversidades, conseguiu construir alguns vínculos afetivos com outros garotos como ele, especialmente quando passou a integrar um grupo de capoeira. A rua, nesse caso, fez o papel da casa, mas não por muito tempo, pois nela ele passaria por outro trauma: a chacina da Candelária, à qual sobreviveu. Uma depoente que também conheceu Sandro narra com detalhes a chacina enquanto mostra o lugar onde tudo ocorreu. Essa fala é confirmada pelo próprio Sandro, que grita com a cabeça para fora da janela do ônibus: "Vocês num mataram os irmãozinho da Candelária, num mataram? Eu estava lá" ${ }^{21}$. Trata-se de um dos poucos momentos em que se tem acesso a fragmentos de sua história por ele mesmo. Assim, percebe-se,

\footnotetext{
20 Diz o autor: “(...) se a casa distingue esse espaço de calma, recuperação e hospitalidade, enfim, tudo aquilo que define a nossa ideia de 'amor', 'carinho' e 'calor humano', a rua é um espaço definido precisamente ao inverso. (...) Sempre temos, nesta ligação, um modo 'oficial' e um popular. Como a casa e rua estivessem sempre travando um combate civilizado e bem-comportado pela posse hegemônica de todo sistema que não chega nunca" (DAMATTA, 1997, p. 57-61).

21 Trecho transcrito de Ônibus 174 (Padilha, 2002).
} 
na articulação entre depoimentos e imagens de arquivo, que, em casa ou na rua, Sandro integrou um clico marcado por situações traumáticas que, em algum momento, resultaria na sua morte por asfixia - realizada por policias no desfecho do sequestro na frente de todo o País.

\section{Considerações finais}

A interpretação do documentário Ônibus 174 como uma narrativa do trauma conduz a discussão a um duplo vetor: de um lado, o imediatismo das imagens da mídia e, de outro, a possibilidade de atribuir sentido a um acontecimento como o retratado pelo filme. Isso não implica tomar a representação do trauma como um índice de absoluta autenticidade ou uma verdade inconteste. Ela é, antes de tudo, uma lente que permite formas de reconhecimento baseadas em diferentes experiências de vitimização, em que se deve sempre considerar o contexto cultural e social. Além disso, a identificação coletiva com o trauma não deixa de ser uma característica de sociedades em que a mídia visual define substancialmente a relação com o passado. Por esses motivos, este trabalho privilegiou a relação entre depoimentos e imagens de arquivo, pois, pelo modo como estão dispostos na montagem, eles permitem, no presente, rever o passado sob outra perspectiva. Ônibus 174 pode também ser visto com um incentivo à produção de materiais audiovisuais que também deem conta das memórias subterrâneas, subalternas ou indesejadas, porque, queiramos ou não, elas também constituem o nosso cotidiano e a nossa história.

Ao elaborar a memória de Sandro, esse documentário restitui a dignidade para alguém que em vida não experimentou tal processo. Se, quando vivo, Sandro não passou de um interminável espectro, Ônibus 174 propõe como desafio questionar os silêncios e as ausências da narrativa midiática hegemônica em suas versões oficiais. O filme concebe uma oportunidade retrospectiva em que se verbaliza as lembranças traumáticas do sequestro. Transforma essas memórias em linguagem narrativa, devendo ser visto como um ato coletivo de narração que cria as condições para a denúncia dos abusos de poder e do silêncio de suas consequências.

Pensar uma narrativa do trauma a partir deste documentário implica também apreender respostas a experiências graves que emergem em condições coletivas. O espaço de tempo entre o lançamento do filme e hoje permite repensar a própria ideia de trauma em um contexto atravessado pela violência, como o brasileiro, especialmente quando se considera sua dimensão audiovisual e midiática, conforme apontado na introdução. Para além do possível efeito narco- 
tizante que o excesso de informações pode provocar, este documentário induz a uma demanda de reparação simbólica que ultrapassa imaginários redutores e cristalizados sobre as questões relacionadas à violência urbana e à marginalidade que circulam na sociedade brasileira.

\section{Referências}

ALEXANDER, Jeffrey C. Toward a theory of cultural trauma. In: ALEXANDER, Jeffrey C. et al. (orgs.). Cultural trauma and collective identity. Berkeley: University of California Press, 2004. https://doi.org/10.1525/california/9780520235946.001.0001

BAKHTIN, Mikhail. O freudismo: um esboço crítico. São Paulo: Perspectiva, 2007.

BALTAR, Mariana. Realidade lacrimosa: diálogos entre o universo do documentário e a imaginação melodramática. 2007. 278 f. Tese (Doutorado em Comunicação) - Programa de Pós-Graduação em Comunicação, UFF, Niterói, 2007.

BENJAMIN, Walter. Charles Baudelaire: um lírico no auge no capitalismo. São Paulo: Brasiliense, 1994.

BERNARDET, Jean-Claude. Cineastas e imagens do povo. São Paulo: Companhia das Letras, 2003.

BRODERICK, Mick; TRAVERSO, Antonio (orgs.). Interrogating trauma. Collective suffering in global arts and media. Londres: Routledge, 2011.

DAMATTA, Roberto. A casa e a rua. 5. ed. Rio de Janeiro: Rocco, 1997.

ERIKSON, Kai. Everything in its path. Nova York: Simon and Schuster, 1976.

HAMBURGER, Esther. Políticas de representação: ficção e documentário em Ônibus 17. In: MOURÃO, Maria Dora e LABAKI, Amir. (orgs.). O cinema do real. São Paulo: Cosac Naify, 2005.

HUYSSEN, Andreas. Seduzidos pela memória: arquitetura, monumentos, mídia. Rio de Janeiro: Aeroplano, 2000.

KEHL, Maria Rita. Tortura e sintoma social. In: TELES, Edson; SAFATLE, Vladimir (orgs.). O que resta da ditadura: a exceção brasileira. São Paulo: Boitempo, 2010.

LEU, Lourraine. Spaces of remembrance \& representation in the city: José Padilha's Ônibus 174. Luso Brazilian Review, Madison, v. 45, n. 2, p. 177-189, 2008. https://doi. org/10.1353/lbr.0.0044

MACDOUGALL, David. Transcultural cinema. Princeton: Princeton University Press, 1998. 
ÔNIBUS 174. Direção de José Padilha. Rio de Janeiro: Zazen Produções, 2002. 1 DVD (130 min), son., color., digital.

RICOEUR, Paul. A memória, a história, o esquecimento. Campinas: Editora Unicamp, 2007.

SARLO, Beatriz. Tempo passado: cultura da memória e guinada subjetiva. São Paulo: Companhia das Letras; Belo Horizonte: Editora UFMG, 2007.

SMELSER, Neil J. Psychological trauma and cultural trauma. In: ALEXANDER, Jeffrey C. et al. (orgs.). Cultural trauma and collective identity. Berkeley: University of California Press, 2004. https://doi.org/10.1525/california/9780520235946.003.0002

SOARES, Luiz Eduardo; BILL, MV; ATHAYDE, Celso. Cabeça de porco. Rio de Janeiro: Objetiva, 2005.

TEIXEIRA, Francisco Elinaldo. Analisando narrativas documentais. In: CATANI, Afrânio Mendes, GARCIA, Wilton; FABRIS, Mariarosaria (orgs.). Estudos de Cinema Socine VI. São Paulo: Nojosa Edições, 2005.

VILLAREJO, Amy. Bus 174 and the living present. Cinema Journal, Austin, v. 46, n. 1, p. 115-120, 2006. https://doi.org/10.1353/cj.2007.0006

WALKER, Janet. Trauma cinema. Berkeley: University of California Press, 2005.

WATERSON, Roxanna. Trajectories of memory: documentary film and the transmission of testimony. History and Anthropology, Londres, v. 18, n. 1, p. 51-73, 2007. https://doi. org/10.1080/02757200701218239

WINSTON, Brian. La vida narrada. Cine documental, Buenos Aires, n. 15, p. 1-13, 2017.

\section{Dados do autor:}

Gustavo Souza da Silva - gustavo03@uol.com.br

Professor do Programa de Pós-Graduação em Comunicação da Universidade Paulista - UNIP. Pós-Doutorado em Comunicação pela Universidade Federal de São Carlos - UFSCAR.

Endereço do autor: Universidade Paulista, Campus Indianópolis. Rua Doutor Bacelar, 1212, Vila Clementino, 04.026-002 - São Paulo (SP) - Brasil 